\title{
Viabilidade do sêmen canino submetido a criopreservação com glicerol e etileno-glicol
}

\author{
Viability of canine semen submitted by cryopreservation with \\ glycerol and ethylene-glycol
}

\author{
Ana Cristina Nery de Castro, ${ }^{*}$ Aline Pacheco, ${ }^{*}$ Daniele Barbosa da Silva, ${ }^{*}$ Débora Silva Gondim, ${ }^{*}$ Tânia Góes de Pinho**
}

\begin{abstract}
Resumo
Com o objetivo de comparar a eficiência dos crioprotetores glicerol e etileno-glicol na criopreservação do sêmen canino, 15 ejaculados foram avaliados quanto à motilidade progressiva, vigor, porcentagem de espermatozóides vivos e de membranas plasmáticas íntegras, imediatamente após a colheita e após a criopreservação. Após a colheita e avaliação (GI), as amostras foram divididas em duas frações, centrifugadas e ressuspensas em diluidor tris-gema acrescido de $6 \%$ de glicerol (GIl) e trisgema acrescido de $6 \%$ de etileno-glicol (GIII) a $37^{\circ} \mathrm{C}$. Após a diluição e envase em palhetas de $0,5 \mathrm{~mL}$, o sêmen foi refrigerado a $5^{\circ} \mathrm{C}$ por 60 minutos e a seguir colocado por 20 minutos no vapor do nitrogênio líquido para o congelamento e posteriormente armazenado em botijão criobiológico. O sêmen foi descongelado em banho-maria a $37^{\circ} \mathrm{C}$ por 30 segundos. As motilidades progressivas observadas nos grupos GI, Gll e GIII foram respectivamente de $85,67 \pm 06,78 \%, 46,53 \pm 20,69 \%$ e $47,67 \pm 20,52 \%$ e o vigor de $4,47 \pm 0,74,2,60 \pm 0,63$ e 2,73 $\pm 0,80$. O percentual de espermatozóides vivos obtido foi de $83,60 \pm 07,88 \%, 48,20 \pm 14,85 \%$ e $46,87 \pm 16,61 \%$ e o percentual de membranas íntegras de $71,73 \pm 15,07 \%, 44,45 \pm 09,18 \%$ e $41,73 \pm 13,33 \%$, respectivamente para os grupos GI, Gll e GIII. Não houve diferença significativa nas características seminais $(P>0,05)$ das amostras criopreservadas com glicerol e etileno-glicol. Verifica-se ainda que houve queda em todos os parâmetros do sêmen após a criopreservação, apesar de não torná-lo inviável. Conclui-se então que, tanto o glicerol quanto o etileno-glicol, podem ser utilizados na criopreservação do sêmen canino.
\end{abstract}

Palavras-chave: sêmen, crioprotetor, cão.

\begin{abstract}
In the aim to compare the efficiency of glycerol and ethylene-glycol cryoprotectors in dog semen's cryopreservation, 15 ejaculate were analyzed a for progressive motility, vigor, live spermatozoon's percentage and complete membranes, immediately after collection (GI) and after cryopreservation in diluents added glycerol (GII) and ethylene-glycol (GIII). After the collection and GI analyze, the samples were divided in two parts, that were centrifuged and added, to the precipitate, the diluents tris-yolk plus $6 \%$ of glycerol (GII) and $6 \%$ ethylene-glycol (GIII) $37^{\circ} \mathrm{C}$. After the dilution, the samples were loaded in straws of $0.5 \mathrm{~mL}$, submitted to $5^{\circ} \mathrm{C}$ refrigeration by 60 minutes, and after to vapor of nitrogen for about 20 minutes. Then they were submersed and stored in liquid nitrogen. The semen was thawed in water bath $37^{\circ} \mathrm{C}$ during 30 seconds. After evaluation the results obtained in this study were: progressive motility $85.67 \pm 6.78 \%, 46.53 \pm 20.69 \%$ and $47.67 \pm 20.52 \%$, as well as vigor of $4.47 \pm 0.74,2.60 \pm 0.63$ and $2.73 \pm 0.80$, live spermatozoon's percentage of $83.60 \pm 7.88 \%, 48.20 \pm 14.85 \%$ and $46.87 \pm 16.61 \%$ and complete membranes of $71.73 \pm 15.07 \%, 44.45 \pm 9.18 \%$ and $41.73 \pm 13.33 \%$, respectively to the groups GI, Gll and GIII. It was observed that there were no difference between seminal characteristics $(P>0.05)$ in the samples cryopreserved with glycerol and ethylene-glycol. Although there was a common drop in all semen parameters after the cryopreservation, the semen quality was even viable. It was concluded that both glycerol and ethylene-glycol, can be used in the criopreservation of dog's semen.
\end{abstract}

Keywords: semen, cryopreservation, dog.

\section{Introdução}

Em caninos, a inseminação artificial com sêmen congelado apresenta resultados modestos, o que impede a sua maior aplicabilidade. A técnica de criopreservação do sêmen canino é uma das limitações observadas. Durante o processo de resfriamento e congelação do sêmen, as células espermáticas sofrem danos causados pela formação de microcristais de gelo intracelular e extracelular, pela desidratação intracelular e toxidade do crioprotetor, levando a alterações na permeabilidade da membrana celular e perda da viabilidade espermática (Watson, 2000). Diversos estudos vêm sendo desenvolvidos na tentativa de se obter um meio diluidor que exerça maior proteção à célula espermática durante os processos de congelação e descongelação. O crioprotetor intracelular mais utilizado na congelação de sêmen de cães

\footnotetext{
*Alunos do Programa de Pós-Graduação em Medicina Veterinária - FV/UFF.

**Professora do Departamento de Patologia e Clínica Veterinária da FV/UFF.
} 
domésticos é o glicerol (Cunha e Lopes, 1999). Entretanto, sabe-se que ele também representa um fator de toxicidade ao espermatozóide (Farstad, 1996). A busca de alternativas para melhorar a viabilidade espermática justifica a avaliação de outros crioprotetores, como por exemplo, o etileno-glicol. Este tem sido utilizado como substância crioprotetora em diversos protocolos de preservação de sêmen ovino (Moraes et al., 1998), eqüino (Neves Neto et al., 1995) e cão (Santos et al., 2001; Cavalcanti et al., 2002; Satzinger, 2002).

Os testes de avaliação espermática são preconizados para verificar os danos sofridos pelos espermatozóides, bem como predizer a capacidade fecundante do sêmen após a criopreservação. A determinação da motilidade progressiva, vigor espermático, da porcentagem de espermatozóides vivos e da integridade de membrana plasmática, pode ser realizada através de testes relativamente de simples execução, e que fornecem informações importantes sobre o movimento e a viabilidade espermática após a criopreservação. $\mathrm{O}$ choque térmico que ocorre durante o processo de criopreservação promove mudanças celulares irreversíveis levando à perda rápida de motilidade, sendo substituída por movimento anormal do espermatozóide (principalmente em círculos), danos à integridade do acrossoma, da membrana plasmática e redução do metabolismo, dentre outros (Graham, 1996). Os testes de motilidade progresssiva e vigor avaliam respectivamente intensidade e qualidade de movimento espermático e os testes de viabilidade espermática e o hiposmótico avaliam a integridade e atividade da membrana plasmática espermática, características importantes nos eventos que precedem a fertilização (Jeyendran et al., 1984).

O objetivo deste estudo foi comparar a qualidade do sêmen canino após a criopreservação com glicerol e etileno-glicol, avaliando-se a motilidade progressiva, vigor espermático, porcentagem de espermatozóides vivos e porcentagem de espermatozóides com membrana plasmática íntegra.

\section{Material e métodos}

Foram utilizados 15 ejaculados previamente selecionados (e" $70 \%$ de motilidade progressiva e d"20\% patologia espermática) de seis cães hígidos. As amostras foram avaliadas imediatamente após a colheita (GI) e após a criopreservação nos meios acrescidos de glicerol (GII) e etileno-glicol (GIII).

Foram avaliados a motilidade progressiva (0-100\%), o vigor espermático (0-5), a porcentagem de espermatozóides vivos, utilizando-se o corante eosina e a porcentagem de espermatozóides com membrana plasmática íntegra, determinada pelo teste hiposmótico (HO). Realizou-se o HO através da preparação de duas amostras de sêmen, uma em solução hiposmótica (150mosmol/L) e outra em solução isosmótica (300mosmol/L), incubadas por 30 minutos em banho-maria a $37^{\circ} \mathrm{C}$ (Inamassu et al. 1999, Souza 2001) e avaliadas segundo a classificação de Jeyendran et al. (1984).
O ejaculado colhido por manipulação digital foi avaliado quanto às características seminais mencionadas e então dividido em duas frações para centrifugação $(300 \mathrm{~g} / 10$ minutos) e posterior diluição em dois meios distintos: trisgema acrescido de $6 \%$ de glicerol e tris-gema acrescido de $6 \%$ de etileno-glicol, a $37^{\circ} \mathrm{C}$. O volume do diluidor a ser adicionado foi calculado com base no volume e concentração da dose inseminante (palheta de $0,5 \mathrm{~mL}$ e $40 \times 10^{6}$ espermatozóides $/ \mathrm{mL}$, respectivamente), motilidade progressiva, volume e concentração do ejaculado

As amostras foram envasadas em palhetas de $0,5 \mathrm{~mL}$, sendo em seguida submetidas à refrigeração $\left(5^{\circ} \mathrm{C} / 60\right.$ minutos). Após foram congeladas em bandejas no vapor de nitrogênio líquido por 20 minutos e depois submersas e armazenadas em nitrogênio líquido.

As amostras foram descongeladas (banho-maria $37^{\circ} \mathrm{C} / 30$ segundos) e imediatamente avaliadas quanto às características seminais citadas.

Para a avaliação dos resultados de cada parâmetro foram realizadas as provas não paramétricas de análise de variância (Teste de ANOVA) e o teste de comparações múltiplas de Tukey-Kramer. O coeficiente de correlação de Pearson foi calculado entre as variáveis, motilidade progressiva, vigor espermático, porcentagem de espermatozóides vivos e porcentagem de membranas íntegras, em cada grupo estudado. As estatísticas calculadas foram consideradas significativas quando $P<0,05$.

\section{Resultados e discussão}

Os resultados da criopreservação seminal obtidos neste estudo são apresentados na Tabela 1 e demonstram que ocorre uma queda significativa $(P<0,05)$, em todos os parâmetros seminais avaliados após o congelamento do sêmen. Fatores como choque térmico e alterações da membrana plasmática do espermatozóide podem ser a razão para o decréscimo da qualidade do sêmen submetido à criopreservação. Não houve diferença $(P>0,05)$ entre a motilidade progressiva e o vigor espermático nos grupos Gll e GIII, confirmando os resultados de Santos et al. (2001), que também verificaram a eficiência do etileno-glicol e glicerol na criopreservação do sêmen de cães. Porém discorda de Cavalcanti et al. (2002) que verificaram melhor viabilidade espermática utilizando glicerol a $7 \%$. A porcentagem de espermatozóides vivos e de membranas íntegras nos ejaculados criopreservados nos dois grupos não apresentaram diferenças $(P>0,05)$.

Tabela 1: Características do sêmen canino avaliado a fresco (GI) e após a criopreservação (Gll e GIII) (média \pm desvio-padrão).

\begin{tabular}{ccccc}
\hline GRUPOS & $\begin{array}{c}\text { Motilidade Progressiva } \\
(\%)\end{array}$ & $\begin{array}{c}\text { Vigor Espermático } \\
(0-5)\end{array}$ & $\begin{array}{c}\text { Espermatozóides Vivos } \\
(\%)\end{array}$ & $\begin{array}{c}\text { Membranas Íntegras } \\
(\%)\end{array}$ \\
\hline GI & $85,67 \pm 06,78^{\mathrm{a}}$ & $4,47 \pm 0,74^{\mathrm{a}}$ & $83,60 \pm 07,88^{\mathrm{a}}$ & $71,73 \pm 15,07^{\mathrm{a}}$ \\
GII & $46,53 \pm 20,69^{\mathrm{b}}$ & $2,60 \pm 0,63^{\mathrm{b}}$ & $48,20 \pm 14,85^{\mathrm{b}}$ & $44,45 \pm 09,18^{\mathrm{b}}$ \\
GIII & $47,67 \pm 20,52^{\mathrm{b}}$ & $2,73 \pm 0,80^{\mathrm{b}}$ & $46,87 \pm 16,61^{\mathrm{b}}$ & $41,73 \pm 13,33^{\mathrm{b}}$ \\
\hline
\end{tabular}

a,bLetras minúsculas diferentes na mesma coluna, diferem entre si $(P<0,05)$ 
Verificou-se ainda neste estudo uma correlação positiva entre todos os parâmetros avaliados no sêmen a fresco e no congelado. A correlação elevada foi verificada entre a motilidade progressiva e a porcentagem de espermatozóides com membranas plasmáticas íntegras para o sêmen a fresco $(r=$ $0,86)$ e congelado com glicerol $(r=0,80)$ e entre motilidade progressiva e porcentagem de espermatozóides vivos $(r=0,83)$ no sêmen criopreservado em etileno-glicol. Resultados semelhantes foram observados por Jeyendran et al. (1984) e

\section{Referências}

CAVALCANTI, M. C. O.; MOURA, C. S.; GUERRA, M. M. P.; SILVA, S. V. Ação crioprotetora do glicerol e etileno-glicol no congelamento do sêmen de cão. Rev. Bras. Reprod. Anim., v. 26, n. 3, p. 174-176, 2002.

CUNHA, I. C. N.; LOPES, M. D. Efeitos da centrifugação sobre a qualidade do sêmen canino. Rev. Bras. Reprod. Anim., v. 23, n. 3, p. 306-308, 1999.

FARSTAD, W. Semen cryopreservation in dogs and foxes. Anim. Reprod. Sci., v. 42, p. 251-260, 1996.

INAMASSU, A.; UECHI, E., LOPES, M. D. 1999. Viabilização do teste hiposmótico em cães e sua relação com outras variáveis espermáticas. Rev. Bras. Reprod. Anim. v. 23, n. 3, p. 302-304.

JEYENDRAN, R. S.; VANDER VEM, H. H.;PEREZ-PELAEZ, M.; CRABO, B. G.; ZANEVELD, L. J. Development of no assay to asses the functional integrity of the human sperm membrane and its relationship to other semen characteristics. J. Reprod. Fertil., v. 70, p. 219-228, 1984.

MORAES, C. N.; NEVES, J. P.; GONÇALVES, P. B. D.; OLIVEIRA, J. F. C; SCHWEITZER, C. M. Criopreservação do sêmen ovino em pellets com etileno-glicol. Ciên. Rural, v. 28, n. 2, p. 287-292, 1998.
Souza et al. (2001) no sêmen a fresco. Porém, isto não justifica a realização de apenas um ou dois testes na avaliação da qualidade do sêmen congelado, pois maior precisão é obtida em testes associados.

\section{Conclusão}

Os resultados deste trabalho sugerem que tanto o glicerol quanto o etileno-glicol, podem ser utilizados na criopreservação do sêmen canino.

NEVES NETO, J. R.; MERCANTE, C. F. J.; ARRUDA, R. P. Fertilidade do sêmen eqüino congelado em etileno-glicol ou glicerol. In: CONGRESSO BRASILEIRO DE REPRODUÇÃO ANIMAL, 11., 1995, Belo Horizonte. Anais...Belo Horizonte: CBRA, 1995, p. 292.

SANTOS, S. E. C.; VANNUCCHI, C. I.; SATZINGER, S.; VISINTIN, J. A. Comparação de dois crioprotetores na congelação de sêmen de cães. Rev. Bras. Reprod. Anim., v. 25, n. 3, p. 472-473, 2001.

SATZINGER, S. Acompanhamento do proestro e estro em fêmeas da raça Dogue Alemão e comparação de 2 técnicas de inseminação artificial com sêmen congelado utilizando o etileno-glicol com crioprotetor. 2002. 70 p. Dissertação (Mestrado) - Faculdade de Medicina Veterinária e Zootecnia, Universidade de São Paulo, São Paulo,. 2002.

SOUZA, F. F.; LOPES, M. D.; BARRETO, S. Avaliação da integridade estrutural e funcional da membrana de espermatozóides de cães utilizando o teste hiposmótico e a coloração com sonda fluorescente. Rev. Bras. Reprod. Anim., v. 25, n. 3, p. 462-464, 2001.

WATSON, P.F. Recent developments and concepts in the cryopreservation of spermatozoa and the assessment of their postthawing function. Reprod. Fert. Dev., v. 7, p. 871-891, 1995. 